\title{
The Impact of Treatment Adherence on Quality of Life Among Type 2 Diabetes Mellitus Patients - Findings from a Cross-Sectional Study
}

This article was published in the following Dove Press journal: Patient Preference and Adherence

\author{
Abdul Majeed (D) \\ Muhammad Rehman' \\ Iltaf Hussain (D) \\ Imran Imran ${ }^{2}$ \\ Muhammad Usman Saleem ${ }^{3}$ \\ Hamid Saeed (1D ${ }^{4}$ \\ Furqan K Hashmi $\mathbb{D}^{4}$ \\ Muqarrab Akbar ${ }^{5}$ \\ Muhammad Asad Abrar \\ Basit Ramzan ${ }^{6}$ \\ Muhammad Omer Chaudhry ${ }^{7}$ \\ Muhammad Islam ${ }^{4}$ \\ Naveed Nisar ${ }^{8}$ \\ Muhammad Fawad Rasool (D) ${ }^{1}$ \\ 'Department of Pharmacy Practice, \\ Faculty of Pharmacy, Bahauddin Zakariya \\ University, Multan, 60800, Pakistan; \\ ${ }^{2}$ Department of Pharmacology, Faculty of \\ Pharmacy, Bahauddin Zakariya University, \\ Multan, 60800, Pakistan; ${ }^{3}$ Department of \\ Biosciences, Faculty of Veterinary \\ Sciences, Bahauddin Zakariya University, \\ Multan, 60800, Pakistan; ${ }^{4}$ University \\ College of Pharmacy, University of the \\ Punjab, Allama Iqbal Campus, Lahore, \\ 54000, Pakistan; ${ }^{5}$ Department of Political \\ Science, Bahauddin Zakariya University, \\ Multan, 60800, Pakistan; ${ }^{6}$ Al Shifa \\ Pharmacy, Multan, Pakistan; ${ }^{7}$ School of \\ Economics, Bahauddin Zakariya \\ University, Multan, 60800, Pakistan; \\ ${ }^{8}$ Department of Pharmaceutics, Faculty of \\ Pharmacy, Bahauddin Zakariya University, \\ Multan, 60800, Pakistan
}

Correspondence: Muhammad Fawad Rasool Department of Pharmacy Practice, Faculty of Pharmacy, Bahauddin Zakariya University

Multan, Multan, Pakistan

Tel +923008639046

Email fawadrasool@bzu.edu.pk
Aim: The current study was conducted to assess the factors contributing to treatment adherence and its impact on the quality of life (QoL) in type 2 diabetes mellitus (T2DM) patients.

Methods: A cross-sectional study was conducted between January 2020 to March 2020 among T2DM patients. The data was collected from T2DM out-patient clinics. The participants were recruited by using a simple random sampling method. To assess the association of demographics with the level of adherence, binary logistics regression analysis was applied. Moreover, the Mann-Whitney $U$-test was used to evaluate the impact of adherence on QoL. Results: A total of 384 patients participated in this study. Amongst them, $60.2 \%$ were male and $39.8 \%$ were female. Low adherence was seen in illiterate patients and patients older than 40 years. The results showed that good QoL in T2DM patients was significantly associated with treatment adherence $(\mathrm{p}=0.004)$.

Conclusion: The finding of the current study showed that the non-adherence prevailed in illiterate strata of the study population and the medication adherence significantly affects the QoL in T2DM patients. These findings suggest that health regulatory agencies should focus on implementing disease-education interventions for improving the adherence to medications in patients with long-term conditions.

Keywords: type 2 diabetes, drug adherence, quality of life

\section{Introduction}

The prevalence of long-term conditions is increasing with every passing day, as $50 \%$ of the visits in primary care clinics are attributed to these conditions. ${ }^{1}$ It has been reported that $70 \%$ of the total health budget is consumed by patients having long-term conditions. ${ }^{1}$ Since patients diagnosed with long-term conditions have to receive treatment for a long period, therefore the adherence to treatment and the quality of life (QoL) have become important parameters for assessing the effectiveness of the disease management plan. The improvement of patients' QoL is very important in the management of long-term conditions, as the poor QoL may lead to the development of disease-associated complications. ${ }^{2}$

Adherence is the integral component for the implementation of pharmacological and non-pharmacological approaches, and it plays an essential role in the effective management of long-term diseases. However, medication non-adherence is a common problem in patients with long-term conditions. ${ }^{3,4}$ Studies have shown that adherence to medications is generally higher in patients with an acute illness, as 
compared to patients with chronic diseases. ${ }^{3,5-7}$ Adherence to medications is around $50 \%$ in the developed world and it is expected to be lower in the developing world. ${ }^{8}$ The patient and medication-related factors associated with treatment non-adherence have been reported in the literature. $^{9}$

QoL is a multidimensional parameter that encompassing the emotional, physical, material, and social well-being of the individual. ${ }^{10,11}$ The healthcare providers goal of therapy in long-term conditions is to maintain or improve the health-related or disease-related QoL. ${ }^{12}$ The QoL is not only associated with the disease manifestations but it is also related to the patient's perception toward their illness. ${ }^{13}$ To improve patient's QoL in long-term conditions, the goal should be to provide personalized care by actively involving them in designing their treatment plans and considering their personal preferences. ${ }^{10}$

According to the world health organization (WHO), Pakistan, in 2019, ranked at fourth position with a diabetic population of 19.4 million. ${ }^{14}$ It is estimated that in 2030, this number will increase to 26.2 million, and in 2045 , it will be ranked number third in the world with a projected diabetic population of 37.12. ${ }^{15}$ Most of the patients are suffering from type 2 diabetes mellitus (T2DM) which comprises $90 \%$ of all diabetes mellitus cases in the world. T2DM is spreading at an alarming rate in Pakistan, therefore it is the need of time to take drastic steps towards its management and improving medication adherence among the diabetic population. ${ }^{14,15}$

In Pakistan, limited information is available regarding the assessment of drug adherence with the QoL of T2DM patients. ${ }^{16}$ Therefore, if a study is conducted that can assess the impact of treatment adherence with the QoL in T2DM patients, it can be of great clinical importance. The current study was conducted to assess the factors contributing to treatment adherence and its effect on the QoL of T2DM patients.

\section{Method and Instruments}

\section{Study Design, Setting, and Participants}

A cross-sectional study was conducted between January 2020 to March 2020. Study participants were T2DM patients. The study was conducted in the outpatient diabetic clinics of Multan, Pakistan. The patients having T2DM with age greater than 25 years, and a diabetic history of more than 1 year were included in this study. The patients were enrolled in the study after signing an informed consent form.

\section{Sample Size and Sampling Method}

According to the International Diabetes Federation (IDF), the prevalence of T2DM in Pakistan was $17.1 \%$ in $2019 .{ }^{17}$ Therefore, a prevalence-based sample size was calculated by using the Raosoft online sample size calculator (Raosoft, Inc. USA) ${ }^{18}$ A sample size of 384 was obtained with a margin of error of $5 \%$, and a Confidence level of $95 \%$. The simple random sampling technique was utilized for the selection of study participants.

\section{Ethical Consideration}

This study was performed in accordance with the ethical standard of the institution and the Declaration of Helsinki and was approved by the ethical committee of the department of pharmacy practice, Bahauddin Zakariya University, Multan, Pakistan (Reference No: Acad/ PRAC/18-20/20). To ensure the privacy and anonymity of patients, their names were replaced by a sequence of allotted numbers. Moreover, the data in hard form were kept in the departmental laboratory locker.

\section{Study Instrument}

In the present study, two instruments were used ie drug attitude inventory- 10 (DAI-10) to assess the treatment adherence and EQ-5D-5L to assess the QoL. Both scales were used after getting the permission.

\section{DAI- 10}

DAI-10 scale is a self-administered and pre-validated scale that comprises of 10 questions based on True/ False responses. ${ }^{19,20}$ In this scale, a 1-point score is awarded to a correct response, and the total score greater than 7 shows high adherence, and a score less than 7 shows low adherence.

\section{QoL Scale}

The QoL scale EQ-5D-5L ${ }^{21}$ consisted of five (5) domains that include mobility, self-care, usual activities, pain/discomfort, and anxiety/ depression. Each domain is comprised of five levels of severity, which include: no problem, slight problem, moderate problem, severe problem, and extreme problem. The EQ-5D preference weight for each health state was not available for the Pakistani population. Therefore, the states were derived from time trade-off (TTO) tariff of preference weights from the general population of the United Kingdom. ${ }^{22}$ 


\section{Data Collection Procedure}

The participants were randomly selected from the outpatient diabetic clinics from selected hospitals of Multan during their visit to the health care providers. Informed consent was taken from each patient before being included in the study, ensuring confidentiality, and describing to them the objectives of the study. Incomplete questionnaires were not included in the final analysis. The numbers of excluded questionnaire were sixty-six. The process of data collection is shown in Figure 1.

\section{Statistical Analysis}

The statistical package for Social Sciences (SPSS) v 25 (Inc., Chicago, USA) was used for statistical analysis. Descriptive statistics were used to summarize the data. The general linear multivariate analysis model (GLM) was used to predict the significant differences between the independent and dependent variables, whereas the Mann-Whitney- $U$ test was used to assess the impact of adherence level on QoL.

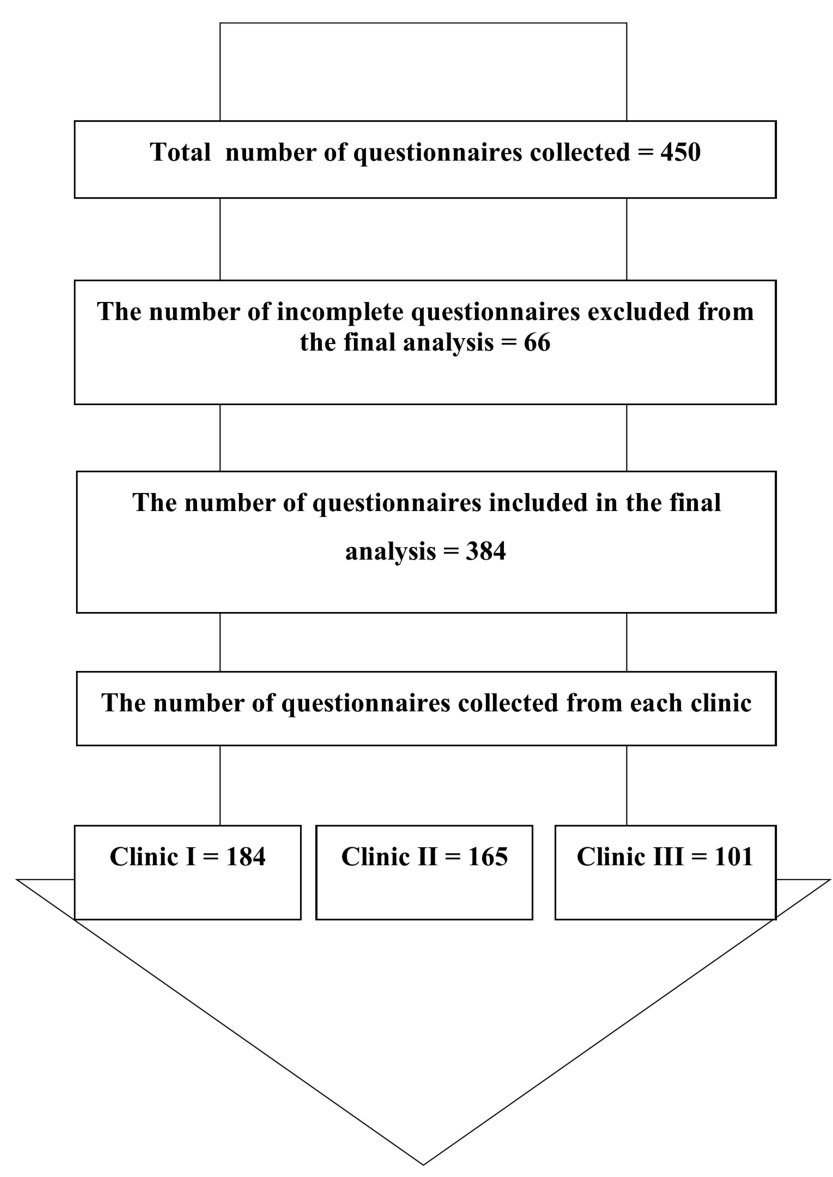

Figure I The data collection process.

\section{Results}

\section{Demographic Characteristics of the}

\section{Participants}

A total of 384 patients participated in this study. The age of most participants was greater than 40 years $(77.1 \%)$. The majority of the participants were male $(60.2 \%)$ and residing in urban areas (59.9\%). Most of the participants were married $(95.8 \%)$ and illiterate (34.1\%). One twenty-one participants were jobless $(31.5 \%)$. The majority of the participants were using oral medications (52.1\%), followed by insulin $(25.8 \%)$ and $22.1 \%$ were taking both insulin and oral medications. The detailed demographics are provided in Table 1.

\section{Medication Adherence}

The majority of the participants gave a positive response regarding the good and beneficial use of medications

Table I Demographic Characteristics of the Participants

\begin{tabular}{|c|c|c|c|}
\hline \multicolumn{2}{|c|}{$\begin{array}{l}\text { Characteristics of the } \\
\text { Participants }\end{array}$} & \multirow{2}{*}{$\begin{array}{l}\text { Frequency } \\
88\end{array}$} & \multirow{2}{*}{$\begin{array}{l}\text { Percentage } \\
22.9\end{array}$} \\
\hline Age & $25-40$ & & \\
\hline & $>40$ & 296 & 77.1 \\
\hline \multirow[t]{2}{*}{ Gender } & Man & 231 & 60.2 \\
\hline & Woman & 153 & 39.8 \\
\hline \multirow[t]{2}{*}{ Marital status } & Married & 368 & 95.8 \\
\hline & Unmarried & 16 & 4.2 \\
\hline \multirow[t]{5}{*}{ Education level } & Illiterate & $|3|$ & 34.1 \\
\hline & Primary & 37 & 9.6 \\
\hline & Secondary & 47 & 12.2 \\
\hline & Graduate & 99 & 25.8 \\
\hline & Postgraduate & 70 & 18.2 \\
\hline \multirow[t]{4}{*}{ Occupation } & Public-sector job & 61 & 15.9 \\
\hline & Private-sector job & 109 & 28.4 \\
\hline & Business & 93 & 24.2 \\
\hline & Unemployed & 121 & 31.5 \\
\hline \multirow[t]{2}{*}{ Residence } & Rural & 154 & 40.1 \\
\hline & Urban & 230 & 59.9 \\
\hline \multirow[t]{3}{*}{ Treatment } & Oral & 200 & 52.1 \\
\hline & Insulin & 99 & 25.8 \\
\hline & Oral + insulin & 85 & 22.1 \\
\hline
\end{tabular}


Table 2 The Participant Responses to DAI-I0 Scale

\begin{tabular}{|l|l|c|c|}
\hline \multicolumn{2}{|l|}{ Questions } & Frequency & Percentage \\
\hline Q1 & True & 298 & 77.6 \\
\hline Q2 & True & 173 & 44.5 \\
\hline Q3 & True & 146 & 38.0 \\
\hline Q4 & True & 282 & 73.4 \\
\hline Q5 & True & 148 & 38.5 \\
\hline Q6 & True & 113 & 29.4 \\
\hline Q7 & True & 293 & 76.3 \\
\hline Q8 & True & 250 & 65.1 \\
\hline Q9 & True & 101 & 26.3 \\
\hline Q10 & True & 251 & 65.4 \\
\hline
\end{tabular}

$(62.0 \%)$ and most of the participants showed fear while taking medications (44.5\%). The majority of the participants were using medication of their choice (38\%) and they believed that the medications make them calmer and more relaxed $(73.4 \%)$. The majority of the participants complained of sluggish and lazy behavior due to medication use $(38.5 \%)$ and most of the participants fell normal when they use their medication $(76.3 \%)$. The participant responses to the DAI-10 scale can be seen in Table 2 .

\section{Impact of Demographics on QoL and Drug Adherence}

In the current study, a significant difference was seen in age $(p<0.001)$ and residency $(p=0.041)$ of the participants to their QoL. Moreover, concerning drug adherence, there was a significant difference across marital status and level of education of the participants. The detail is given in Table 3 .

\section{QoL}

In terms of mobility, most of the participants were having no problem (44\%) followed by a slight (29.2\%) and moderate problem $(21.4 \%)$. The majority of participants had a slight problem in performing self-care (34.1\%) while $56.3 \%$ had a slight problem in carrying usual activities. Most of the participants felt pain/discomfort (49.5\%) and depression (38\%). The QoL of the participants can be seen in Table 4.

A total of 46 different health states were reported by the study participants, whereby 13 (3.4\%) showed no problems in all five domains while 124 (32.4\%)

Table 3 The Association of Demographics with the Level of Adherence and Quality of Life by Using the Multivariate Analysis

\begin{tabular}{|c|c|c|c|c|}
\hline Source & Dependent Variable & Mean Square & F-value & P-value \\
\hline \multirow[t]{2}{*}{ Age } & QoL & 1202.07 & 100.36. & $<0.001 *$ \\
\hline & Drug Adherence & 0.142 & 0.04 & 0.842 \\
\hline \multirow[t]{2}{*}{ Gender } & QoL & 38.937 & 3.045 & 0.124 \\
\hline & Drug Adherence & 0.222 & 0.082 & 0.783 \\
\hline \multirow[t]{2}{*}{ Marital status } & QoL & 4.04 & 0.337 & 0.56 \\
\hline & Drug Adherence & 31.11 & 8.71 & $0.003^{*}$ \\
\hline \multirow[t]{2}{*}{ Educational level } & QoL & 7.632 & 0.597 & 0.677 \\
\hline & Drug Adherence & 42.012 & 15.478 & $0.00 I^{*}$ \\
\hline \multirow[t]{2}{*}{ Occupation } & QoL & 14.875 & 1.163 & 0.389 \\
\hline & Drug Adherence & 0.557 & 0.205 & 0.890 \\
\hline \multirow[t]{2}{*}{ Treatment } & QoL & 16.837 & 1.317 & 0.327 \\
\hline & Drug Adherence & 3.464 & 1.276 & 0.337 \\
\hline \multirow[t]{2}{*}{ Residence } & QoL & 80.080 & 6.263 & $0.04 I^{*}$ \\
\hline & Drug Adherence & 0.051 & 0.019 & 0.895 \\
\hline
\end{tabular}

Note: $*_{p}<0.05$.

Abbreviation: QoL, quality of life. 
Table 4 The Quality of Life of the Participants

\begin{tabular}{|l|l|l|l|l|l|}
\hline \multirow{2}{*}{ Level of Problems } & \multicolumn{4}{l}{ QoL Domains } & \multicolumn{4}{l|}{} \\
\cline { 2 - 6 } & Mobility & Self-Care & Usual Activity & Pain/ Discomfort & Anxiety/ Depression \\
\hline Level I (No Problem) & $169(44 \%)$ & $178(46.4 \%)$ & $72(18.8 \%)$ & $60(15.6 \%)$ & $93(24.2 \%)$ \\
\hline Level 2 (Slight Problem) & $112(29.2 \%)$ & $131(34.1 \%)$ & $216(56.3 \%)$ & $190(49.5 \%)$ & $146(38 \%)$ \\
\hline Level 3 (Moderate Problem) & $82(21.4 \%)$ & $62(16.1 \%)$ & $60(15.6 \%)$ & $66(17.2 \%)$ & $70(18.2 \%)$ \\
\hline Level 4 (Severe Problem) & $21(5.5 \%)$ & $13(3.4 \%)$ & $30(7.8 \%)$ & $29(7.6 \%)$ & $38(9.9 \%)$ \\
\hline Level 5 (Extreme problem) & 0 & 0 & $6(1.6 \%)$ & $39(10.2 \%)$ & $37(9.6 \%)$ \\
\hline
\end{tabular}

respondents pointed out no problem in mobility and selfcare domain while moderate problem in pain and anxiety/ depression domain (Supplementary Table S1).

\section{Impact of Level of Adherence on QoL}

The independent-samples Mann Whitney $U$-test revealed that the good quality of life in T2DM patients was significantly associated with a high level of adherence $(\mathrm{p}=0.004)$ (Supplementary Figure S1).

\section{Discussion}

In the present study, we have assessed the relationship between treatment adherence and QoL of T2DM patients. Our results showed that the marital status and level of literacy were significantly associated with treatment adherence. Moreover, it was observed that the good QoL in the T2DM patients was associated with higher medication adherence rates.

Adherence to the treatment is an important factor in the management of chronic conditions. ${ }^{23}$ Poor medication adherence is a major barrier to the management of T2DM. Poor medication adherence is also associated with health expenditures. ${ }^{24}$ The medication adherence rate identified in this study was $33.3 \%$. This number was low as compared to a similar study from the United State of America (79\%), ${ }^{25}$ but it was consistent with a study reported from Indonesia (29.7\%). ${ }^{26}$ This comparison indicates that in developed countries, there is a wellestablished healthcare system where the healthcare team works together to deliver health and provide individualized treatment (if needed) to the patients. While in developing countries with a focus on Pakistan, due to poor healthcare system, poor quality of pharmaceutical care to the patients, and an increase in the cost of therapy may contribute to the low treatment adherence in the T2DM population. The incorporation of pharmaceutical care in the healthcare system has significantly contributed to treatment adherence in patients with long-term conditions. ${ }^{27}$

It has been reported that the participants with a higher lower literacy level, living with the disease for a long time had a negative effect on their QoL and treatment adherence. $^{26,28}$ In the current study, it was seen that the literacy level of the participants was significantly associated with higher treatment adherence and that is consistent with the previous reports. ${ }^{29,30}$ This finding highlights the need for focused health literacy programs in the illiterate stratum of the community.

In the current study, most of the participants report slight to moderate problems in terms of QoL. This finding was similar to the reported studies from Pakistan ${ }^{16}$ and Indonesia. $^{26}$ The QoL in T2DM patients is an important outcome parameter. Therefore, it is the primary goal of the healthcare providers to formulate sustainable health goals for the betterment of QoL of diabetic patients. ${ }^{31}$

Patients with chronic conditions are more likely to have physical, psychological, and social health issues as compared to patients with acute illnesses. ${ }^{32-34}$ In this study, a positive relationship between QoL and treatment adherence was seen in T2DM patients. The patients with poor treatment adherence showed a lower QoL and those with good treatment adherence showed a good QoL. This result was consistent with the previous reports in which the DAI-10 scale was used with similar cutoff-points. ${ }^{33,34}$ Moreover, medication adherence can be improved by focusing on patient counseling, disease education, and by decreasing the complexity of the prescribed dosing regimen. According to WHO, improving adherence to treatment in chronic conditions can significantly produce health and economic benefits. ${ }^{35}$

Treatment non-adherence leads to disease-related complications and can increase the direct and indirect 
healthcare costs. ${ }^{3}$ It is reported that in adults, around $10 \%$ of hospital admissions can be attributed to treatment nonadherence. $^{36}$ Moreover, the $10 \%$ increase in treatment adherence in diabetic patients can decrease the annual healthcare costs by $8.6-28.9 \%{ }^{35}$ Also, non-adherence to medication can develop an uncontrolled disease condition that can have a considerable effect on patients' QoL, as it may lead to physical, social, and financial problems. ${ }^{37}$

\section{Practice Implications and Future Recommendation}

The present study can have many implications at the national and global levels. The poor QoL and treatment non-adherence in T2DM patients is alarming. The Physician and Pharmacist should emphasize the importance of treatment adherence in the management of chronic conditions to their patients. Moreover, the barriers to treatment adherence in patients with chronic conditions can be addressed by allowing their active participation in designing personalized disease management plans.

\section{Conclusion}

The current study showed that T2DM patients with a higher level of treatment adherence showed good QoL. Moreover, the literacy level of T2DM patients was significantly associated with their level of adherence. The treatment adherence can be improved by simplifying the prescribed dosing regimen and ensuring appropriate patient counseling. To increase treatment adherence in T2DM patients, there is a need for the initiation of diabetes education programs at the community levels.

\section{Author Contributions}

All authors made substantial contributions to conception and design, acquisition of data, or analysis and interpretation of data; took part in drafting the article or revising it critically for important intellectual content; agreed to submit to the current journal; gave final approval of the version to be published; and agree to be accountable for all aspects of the work.

\section{Disclosure}

The authors report no conflicts of interest in this work.

\section{References}

1. Uk department of health. Long Term Conditions Compendium of Information Third Edition; 2020. Available from: https://assets.publish ing.service.gov.uk/government/uploads/system/uploads/attachment_ data/file/216528/dh_134486.pdf. Accessed 05 October 2020.
2. Adriaanse MC, Drewes HW, Van Der Heide I, Struijs JN, Baan CA. The impact of comorbid chronic conditions on quality of life in type 2 diabetes patients. Quality Life Res. 2016;25(1):175-182. doi:10.1007/s11136-015-1061-0

3. Osterberg L, Blaschke T. Adherence to medication. $N$ Engl J Med. 2005;353(5):487-497. doi:10.1056/NEJMra050100

4. World Health Organization. Noncommunicable Diseases and Mental Health; 2020. Available from: https://www.who.int/mip/2003/pro gress/en/nmhmip2003.pdf. Accessed 5 November, 2020.

5. Jackevicius CA. Adherence with statin therapy in elderly patients with and without acute coronary syndromes. JAMA. 2002;288 (4):462-467. doi:10.1001/jama.288.4.462

6. Caro JJ, Salas M, Speckman JL, Raggio G, Jackson JD. Persistence with treatment for hypertension in actual practice. CMAJ. 1999;160(1):31-37.

7. Haynes RB, McDonald HP, Garg AX. Helping patients follow prescribed treatment: clinical applications. JAMA. 2002;288 (22):2880-2883. doi:10.1001/jama.288.22.2880

8. Khayyat SM, Mohamed MMA, Khayyat SMS, et al. Association between medication adherence and quality of life of patients with diabetes and hypertension attending primary care clinics: a cross-sectional survey. Quality Life Res. 2019;28(4):1053-1061. doi:10.1007/s11136-018-2060-8

9. Marcum ZA, Sevick MA, Handler SM. Medication nonadherence: a diagnosable and treatable medical condition. JAMA. 2013;309 (20):2105-2106. doi:10.1001/jama.2013.4638

10. Choudry MI, Stewart K, Woodhead T. The Royal College of Physician's Quality Improvement Hub - how can it help physicians to improve patient care? Future Hospital J. 2016;3(3):211-216. doi:10.7861/futurehosp.3-3-211

11. Davis MV, Mahanna E, Joly B, et al. Creating quality improvement culture in public health agencies. Am J Public Health. 2014;104(1): e98-104. doi:10.2105/ajph.2013.301413

12. Porterfield DS, Marcial LH, Brown S, Throop C, Pina J. Evaluation of a Quality Improvement Resource for Public Health Practitioners. Public Health Rep. 2017;132(2):140-148. doi:10.1177/0033354916689609

13. Martin JC, Avant RF, Bowman MA, et al. The Future of Family Medicine: a collaborative project of the family medicine community. Ann Fam Med. 2004;2 Suppl 1(Suppl 1):S3-32. doi:10.1370/afm.130

14. World Health Organization. Diabetic country profile; 2020. Available from: https://www.who.int/diabetes/country-profiles/pak_en.pdf. Accessed 5 November, 2020.

15. Sherin A. National diabetes action plan of Pakistan: need and challenges. Khyber Med Univ J. 2015;7(1):1-2.

16. Nazir R, Hassali MA, Saleem F, Bashir S, Aljadhey H. Does adherence to the therapeutic regimen associate with health related quality of life: findings from an observational study of type 2 diabetes mellitus patients in Pakistan. Pak J Pharm Sci. 2017;30 (6):2159-2165.

17. International Diabetic Federation. IDF DIABETES ATLAS 9th Edition. 9th ed. 2019.

18. Raosoft I. Sample size calculator; 2004. Available From: http://www. raosoft.com/samplesize.html. Accessed 15 February, 2021

19. Hogan TP, Awad AG, Eastwood R. A self-report scale predictive of drug compliance in schizophrenics: reliability and discriminative validity. Psychol Med. 1983;13(1):177-183. doi:10.1017/ S0033291700050182

20. Saleem F, Hassali MA, Shafie AA, Awad AG, Bashir S. Association between knowledge and drug adherence in patients with hypertension in Quetta, Pakistan. Tropical J Pharm Res. 2011;10:2.

21. Euqator Group. EQ-5D-5L; 2020. Available from: https://euroqol. org/eq-5d-instruments/eq-5d-51-about/. Accessed 05 November 2020.

22. Dolan P, Gudex C, Kind P, Williams A. A Social Tariff for EuroQol: Results from a UK General Population Survey. 1995.

23. Bassett SM, Schuette SA, O’Dwyer LC, Moskowitz JT. Positive affect and medication adherence in chronic conditions: a systematic review. Health Psychol. 2019;38(11):960. doi:10.1037/hea0000778 
24. Polonsky WH, Henry RR. Poor medication adherence in type 2 diabetes: recognizing the scope of the problem and its key contributors. Patient Preference Adherence. 2016;10:1299. doi:10.2147/PPA.S106821

25. Boccuzzi SJ, Wogen J, Fox J, Sung JC, Shah AB, Kim J. Utilization of oral hypoglycemic agents in a drug-insured U.S. population. Diabetes Care. 2001;24(8):1411-1415. doi:10.2337/diacare.24.8.1411

26. Perwitasari DA, Urbayatun S. Treatment adherence and quality of life in diabetes mellitus patients in Indonesia. Sage Open. 2016;6 (2):2158244016643748. doi:10.1177/2158244016643748

27. Shao H, Chen G, Zhu C, et al. Effect of pharmaceutical care on clinical outcomes of outpatients with type 2 diabetes mellitus. Patient Preference Adherence. 2017;11:897. doi:10.2147/PPA. S92533

28. Saleh F, Mumu SJ, Ara F, Hafez MA, Ali L. Non-adherence to selfcare practices \& medication and health related quality of life among patients with type 2 diabetes: a cross-sectional study. BMC Public Health. 2014;14(1):431. doi:10.1186/1471-2458-14-431

29. Ueno H, Ishikawa H, Suzuki R, et al. The association between health literacy levels and patient-reported outcomes in Japanese type 2 diabetic patients. SAGE Open Med. 2019;7:2050312119865647. doi:10.1177/2050312119865647

30. Rodrigues da Rocha M, Domingas dos Santos S, Rafaela de Moura K,de Sousa Carvalho L, Holanda de Moura I, Vilarouca da Silva AR. Health literacy and adherence to drug treatment of type 2 diabetes mellitus. Escola Anna Nery. 2019;23:2.
31. Amelia R, Lelo A, Lindarto D, Mutiara E. Quality of life and glycemic profile of type 2 diabetes mellitus patients of Indonesian: a descriptive study. InIOP Conf Series. 2018. doi:10.1088/1755$1315 / 125 / 1 / 012171$

32. Lam CL, Lauder IJ. The impact of chronic diseases on the health-related quality of life (HRQOL) of Chinese patients in primary care. Fam Pract. 2000;17(2):159-166. doi:10.1093/fampra/17.2.159

33. Azar FF, Solhi M, Chabaksvar F. Investigation of the quality of life of patients with hypertension in health centers. J Educ Health Promot. 2020;9(1):185. doi:10.4103/jehp.jehp_741_19

34. ElShazly HM, Hegazy NN. Socioeconomic determinants affecting the quality of life among diabetic and hypertensive patients in a rural area, Egypt. J Family Med Prim Care. 2017;6(1):141-145. doi:10.4103/jfmpc.jfmpc_31_17

35. Saleem F, Hassali MA, Shafie AA. A cross-sectional assessment of health-related quality of life (HRQoL) among hypertensive patients in Pakistan. Health Expect. 2014;17(3):388-395. doi:10.1111/j.13697625.2012.00765.x

36. Iqbal Q, Ul Haq N, Bashir S, Bashaar M. ul Haq N, Bashir S, Bashaar M. Profile and predictors of health related quality of life among type II diabetes mellitus patients in Quetta city, Pakistan. Health Qual Life Outcomes. 2017;15(1):142. doi:10.1186/s12955-017-0717-6

37. Brown MT, Bussell JK. Medication adherence: WHO cares? Mayo Clinic Proc. 2011;86(4):304-314. doi:10.4065/mcp.2010.0575
Patient Preference and Adherence

\section{Publish your work in this journal}

Patient Preference and Adherence is an international, peer-reviewed, open access journal that focusing on the growing importance of patient preference and adherence throughout the therapeutic continuum. Patient satisfaction, acceptability, quality of life, compliance, persistence and their role in developing new therapeutic modalities and compounds to optimize clinical outcomes for existing disease

\section{Dovepress}

states are major areas of interest for the journal. This journal has been accepted for indexing on PubMed Central. The manuscript management system is completely online and includes a very quick and fair peer-review system, which is all easy to use. Visit http:// www.dovepress.com/testimonials.php to read real quotes from published authors. 